\title{
Steady Flow in a Curved Pipe with Circular Cross-Section. Comparison of Numerical and Experimental Results
}

\author{
M.A. Petrakis ${ }^{*}$, G.T. Karahalios and S. Kaplanis
}

Technological Educational Institute of Patras, Department of Mechanical Engineering, M. Alexandrou 1, Patra, Greece,

\begin{abstract}
Numerical solution has been obtained of the equations of motion of a viscous incompressible fluid in a curved annular conduit with circular cross-section. These equations are approximated by finite-difference equations which are of the second-order accuracy with respect to the grid sizes. The computed results are presented for the range $96 \leq \mathrm{D} \leq 8000$, where D is the Dean number of the flow and for various sizes of core radii, the limiting cases of a very large and a very small core being also studied. It is shown that in the case of a small core radius, the variation of the Dean number affects significantly the flow properties, situation which is not observed when the core radius is large.
\end{abstract}

\section{INTRODUCTION}

Steady flow into curved pipes has been studied extensively due to the applications in engineering. Annular flow is an important feature in double-pipe heat exchangers, in chemical mixing and drying machinery.

The theoretical exploration of the steady flow in a pipe of slight curvature was first considered by Dean $[1,2]$. It was shown that the effect of curvature is to reduce the flux, and that the non-dimensional volume flux depends only on the so-called Dean number $\mathrm{K}=\frac{2 \alpha}{\mathrm{R}\left(\mathrm{W}_{\text {max }} \alpha / v\right)^{2}}$ where $\alpha$ and $\mathrm{R}$ are, respectively, the radius and the radius of curvature of the pipe, $\mathrm{W}_{\max }$ is the maximum axial velocity in a straight pipe of the same radius and pressure gradient and $v$ is the kinematic viscosity of the fluid. Dean's solution is valid for $\mathrm{K} \leq 576$. Dean's work was extended by McConalogue and Srivastava [3] who adopted the parameter $\mathrm{D}=\left(\frac{2 \alpha}{\mathrm{R}}\right)^{\frac{1}{2}}\left(\frac{\mathrm{G} \alpha^{3}}{\mu \nu}\right)$ in place of $\mathrm{K}$, where $\mu$ is the coefficient of viscosity and $\mathrm{G}$ is the constant pressure gradient. The relation between $D$ and $K$ is given by $D=4 K^{1 / 2}$. By means of Fourier analysis they reduced the equations of motion to ordinary differential equations which are solved numerically in the range $96 \leq \mathrm{D} \leq 605.72$. In terms of the Dean number $\mathrm{D}$ defined by McConalogue and Srivastava [3], experimental evidence indicated that the upper limit of the laminar-flow range was approximately $\mathrm{D}=5000$. Truesdell and Adler [4] bridged partially the gap by obtaining results up to $D=3578$ through numerical procedure, working on a helically coiled pipe of moderate pitch. An other approach was given by Greenspan [5]. A combination of central, forward and

*Address correspondence to this author at the Technological Educational Institute of Patras, Department of Mechanical Engineering, M. Alexandrou 1, Patra, Greece; E-mail: petrakis@teipat.gr backward difference scheme was used to approximate the equations of motion by difference equations. The method was applied for a variety of values of D between zero and 5000. The spacing in the radial and in the angular direction was the same for all $\mathrm{D}(\Delta \mathrm{r}=0.1$ and $\Delta \theta=\pi / 18$, respectively). Among the most reliable studies, is that Collins and Denis [6] who replaced all partial derivatives in the equations of motion by central-difference approximations. They used three pairs of grid sizes $(\Delta \mathrm{r}=0.1$ and $\Delta \theta=\pi / 18, \Delta \mathrm{r}=0.05$ and $\Delta \theta=\pi / 36, \Delta r=0.025$ and $\Delta \theta=\pi / 72)$ for $96 \leq \mathrm{D} \leq 5000$. An accepted criterion of accuracy was adopted as a terminating condition to the solution procedure of the difference equations which were of second-order accuracy was adopted as a terminating condition to the solution procedure of the difference equations at all grid points. In a subsequent paper Dennis [7] approximated the Navier-Stokes equations of motion by finite-difference equations which were of secondorder accuracy with respect to the grid sizes. Annular flow in curved pipes involving heat transfer has been studied by Karahalios [8], and Choi and Park [9], while possible effects of artery catheterization on atherosclerosis has been studied by Karahalios and Petrakis [10].

In the present work the fully developed flow of a viscous incompressible fluid in a curved annular pipe is studied numerically. The procedure covers the range $96 \leq \mathrm{D} \leq 8000$ and refers to both small or large radius ratio $\mathrm{k}$ (the number $\mathrm{k}$ is defined as the ratio of the radius $k \alpha$ of the pipe to the radius $\alpha$ of the core). The equations of motion are approximated in terms of finite differences at the grid points of the annular domain. In particular, the approximation is based on a relaxation method described by Allen and Southwell [11]. Five pairs of grid sizes are used for $96 \leq \mathrm{D} \leq 8000$ and the degree of accuracy of the calculated results is determined by a test which terminates the iterative procedure.

Results concerning the axial velocity have been obtained for certain radius ratios $\mathrm{k}$, including the cases of $\mathrm{k} \rightarrow 1$ and $\infty$. In the first case $(\mathrm{k}=1.1)$ the flow is reduced to the 
Couette type, while in the second case $(\mathrm{k}=1000)$ comparison of the values of certain flow parameters of the present study with the previous results shows a satisfactory agreement. It is also shown that the axial core affects seriously the secondary flow, the influence being stronger when $\mathrm{k}$ gets larger. In addition to the two well-known vortices of the secondary flow appearing in a plain curved tube, two smaller vortices are formed close to the axial core, their origin located at the outward side of the bend. An interesting feature of the flow in the annular pipe is the flux. It is shown that the flux is reduced compared to that in a straight pipe when the Dean number is large.

Finally, the results concerning the axial flow are compared with those obtained by experiments. It is shown that the results due to the theoretical analysis are in a very good agreement in the case that the radius ratio $\mathrm{k}$ tend to $\infty$.

\section{EQUATION OF MOTION}

We consider the steady incompressible flow of a viscous fluid within a loosely coiled curved annular pipe of circular cross-section, and of radius $k \alpha(k>1), \alpha$ being the radius of the coaxial core. The pipe is coiled in a circle of radius $\mathrm{L}$ about the axis $\mathrm{Oz}$. In the present work the ratio $\mathrm{k} \alpha / \mathrm{L}$ will be assumed very small. The geometry of the pipe suggests the use of toroidal coordinates $\mathrm{r}^{*}, \theta$ and $\varphi$ (Fig. 1). Let $\mathrm{U}, \mathrm{V}$ and $\mathrm{W}$ be the velocity components that correspond to these coordinates. In addition, let $\mathrm{p}$ denote pressure, $\rho$ the density and $v$ the kinematic viscosity.

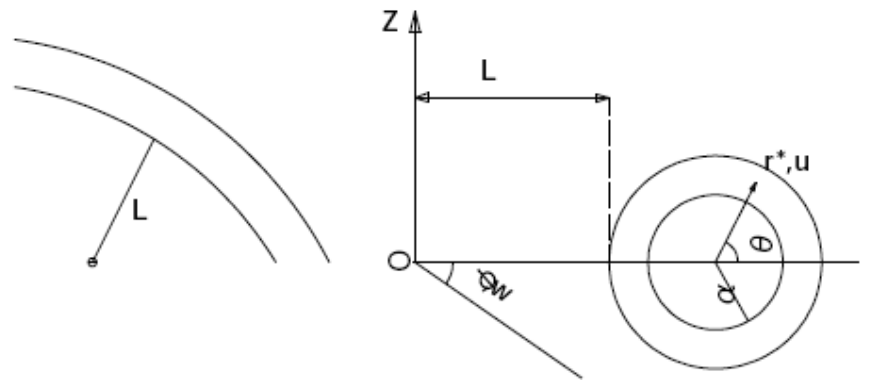

Fig. (1). Toroidal coordinate system.

The equations of motion are

$$
\begin{aligned}
& \mathrm{U} \frac{\partial \mathrm{U}}{\partial \mathrm{r}^{*}}+\frac{\mathrm{V}}{\mathrm{r}^{*}} \frac{\partial \mathrm{U}}{\partial \theta}-\frac{\mathrm{V}^{2}}{\mathrm{r}^{*}}-\frac{\mathrm{W}^{2} \cos \theta}{\mathrm{L}} \\
& =-\frac{\partial}{\partial \mathrm{r}^{*}}\left(\frac{\mathrm{p}}{\rho}\right)-\frac{\mathrm{v}}{\mathrm{r}^{*}} \frac{\partial}{\partial \theta}\left(\frac{\partial \mathrm{V}}{\partial \mathrm{r}^{*}}+\frac{\mathrm{V}}{\mathrm{r}^{*}}-\frac{1}{\mathrm{r}^{*}} \frac{\partial \mathrm{U}}{\partial \theta}\right)
\end{aligned}
$$

$\mathrm{U} \frac{\partial \mathrm{V}}{\partial \mathrm{r}^{*}}+\frac{\mathrm{V}}{\mathrm{r}^{*}} \frac{\partial \mathrm{V}}{\partial \theta}+\frac{\mathrm{UV}}{\mathrm{r}^{*}}+\frac{\mathrm{W}^{2} \sin \theta}{\mathrm{L}}$

$=\frac{1}{\mathrm{r}^{*}} \frac{\partial}{\partial \theta}\left(\frac{\mathrm{p}}{\rho}\right)+v \frac{\partial}{\partial \mathrm{r}^{*}}\left(\frac{\partial \mathrm{V}}{\partial \mathrm{r}^{*}}+\frac{\mathrm{V}}{\mathrm{r}^{*}}-\frac{1}{\mathrm{r}^{*}} \frac{\partial \mathrm{U}}{\partial \theta}\right)$

$$
\begin{aligned}
& \mathrm{U} \frac{\partial \mathrm{W}}{\partial \mathrm{r}^{*}}+\frac{\mathrm{V}}{\mathrm{r}^{*}} \frac{\partial \mathrm{W}}{\partial \theta} \\
& =-\frac{1}{\mathrm{~L}} \frac{\partial}{\partial \varphi}\left(\frac{\mathrm{p}}{\rho}\right)+v\left(\frac{\partial^{2} \mathrm{~W}}{\partial \mathrm{r}^{2}}+\frac{1}{\mathrm{r}^{*}} \frac{\partial \mathrm{W}}{\partial \mathrm{r}^{*}}+\frac{1}{\mathrm{r}^{*^{2}}} \frac{\partial^{2} \mathrm{~W}}{\partial \theta^{2}}\right)
\end{aligned}
$$

where $-\frac{\partial p}{\partial \varphi}$ is the pressure gradient at the ends of the pipe.

The equation of continuity is

$\frac{\partial \mathrm{U}}{\partial \mathrm{r}^{*}}+\frac{\mathrm{U}}{\mathrm{r}^{*}}+\frac{1}{\mathrm{r}^{*}} \frac{\partial \mathrm{V}}{\partial \theta}=0$

The flow is fully developed, thus independent of $\varphi$. Eq. (4) is satisfied by introducing the streamfunction F for flow in the cross-section such that

$\mathrm{r}^{*} \mathrm{U}=\frac{\partial \mathrm{F}}{\partial \theta}$ and $\mathrm{V}=-\frac{\partial \mathrm{F}}{\partial \mathrm{r}^{*}}$.

By cross-differentiation of Eqs. (1) and (2) and after dropping the pressure terms we conclude the following form for the equations of motion:

$\left(-\frac{\partial \mathrm{F}}{\partial \theta} \frac{\partial}{\partial \mathrm{r}^{*}}+\frac{\partial \mathrm{F}}{\partial \mathrm{r}^{*}} \frac{\partial}{\partial \theta}\right) \cdot \nabla_{1}^{2}$

$\mathrm{F}+\frac{2 \mathrm{~W}}{\mathrm{~L}}\left(\mathrm{r}^{*} \frac{\partial \mathrm{W}}{\partial \mathrm{r}^{*}} \sin \theta+\frac{\partial \mathrm{W}}{\partial \theta} \cos \theta\right)=-v \cdot \mathrm{r}^{*} \nabla_{1}^{4} \mathrm{~F}$

$\frac{1}{\mathrm{r}^{*}}\left(-\frac{\partial \mathrm{F}}{\partial \mathrm{r}^{*}} \frac{\partial \mathrm{W}}{\partial \theta}+\frac{\partial \mathrm{F}}{\partial \theta} \frac{\partial \mathrm{W}}{\partial \mathrm{r}^{*}}\right)=\frac{\mathrm{G}}{\rho}+\mathrm{v} \cdot \nabla_{1}^{2} \mathrm{~W}$

where $G=-\frac{1}{L} \frac{\partial P}{\partial \varphi}$ and $\nabla_{1}^{2}=\frac{\partial^{2}}{\partial \mathrm{r}^{* 2}}+\frac{1}{\mathrm{r}^{*}} \frac{\partial}{\partial \mathrm{r}^{*}}+\frac{1}{\mathrm{r}^{* 2}} \frac{\partial^{2}}{\partial \theta^{2}}$

Introducing in addition the non-dimensional variables

$$
\begin{aligned}
& \mathrm{r}^{*}=\mathrm{k} \alpha \mathrm{r}, \quad \mathrm{U}=\mathrm{v} \frac{\mathrm{u}}{\mathrm{k} \alpha}, \quad \mathrm{V}=\mathrm{v} \frac{\mathrm{v}}{\mathrm{k} \alpha}, \quad \mathrm{F}=\mathrm{v} \cdot \mathrm{f} \\
& \mathrm{W}=\mathrm{v}\left[\frac{\mathrm{L}}{2(\mathrm{k} \alpha)^{3}}\right]^{1 / 2} \mathrm{w}
\end{aligned}
$$

and substituting in the preceding equations we obtain

$$
\begin{aligned}
& \left(\frac{\partial \mathrm{f}}{\partial \mathrm{r}} \frac{\partial}{\partial \theta}-\frac{\partial \mathrm{f}}{\partial \theta} \frac{\partial}{\partial \mathrm{r}}\right) \nabla^{2} \mathrm{f}+\mathrm{w}\left(\mathrm{r} \frac{\partial \mathrm{w}}{\partial \mathrm{r}} \sin \theta+\frac{\partial \mathrm{w}}{\partial \theta} \cos \theta\right)=-\mathrm{r} \nabla^{4} \mathrm{f} \\
& \frac{1}{\mathrm{r}}\left(-\frac{\partial \mathrm{f}}{\partial \mathrm{r}} \frac{\partial \mathrm{w}}{\partial \theta}+\frac{\partial \mathrm{f}}{\partial \theta} \frac{\partial \mathrm{w}}{\partial \mathrm{r}}\right)=\mathrm{D}+\nabla^{2} \mathrm{w}
\end{aligned}
$$

where

$$
\mathrm{D}=\left(\frac{2}{\mathrm{~L}} \mathrm{Ka}\right)^{1 / 2} \mathrm{G} \frac{\mathrm{K}^{3} \mathrm{a}^{3}}{\mu \cdot v} \text { and } \nabla^{2}=\frac{\partial^{2}}{\partial \mathrm{r}^{2}}+\frac{1}{\mathrm{r}} \frac{\partial}{\partial \mathrm{r}}+\frac{1}{\mathrm{r}^{2}} \frac{\partial^{2}}{\partial \theta^{2}} .
$$

The velocity components must vanish at the surface of the tube and of the core, $r=1$ and $r=1 / k$, respectively, and hence

$$
\mathrm{w}=\mathrm{f}=\frac{\partial \mathrm{f}}{\partial \mathrm{r}}=0 \text { at } \mathrm{r}=1 \text { and } \mathrm{r}=1 / \mathrm{k} \text {. }
$$

The flow is symmetrical about the line $\theta=0, \pi$ from which it follows that 
$f(r,-\theta)=-f(r, u), w(r,-\theta)=w(r, \theta)$,

while $\mathrm{f}=\frac{\partial \mathrm{w}}{\partial \theta}=0$ on the line itself.

\section{Numerical Solution}

The upper semicircular annular region $1 / \mathrm{k} \leq \mathrm{r} \leq 1,0 \leq \theta \leq \pi$ (Fig. 2), is divided into a grid formed by the radial lines $\theta=\mathrm{jg}$ and the semi-circles $r=1 / k+i h$, where $\mathrm{h}, \mathrm{g}$ denote the size of the grid in the increasing radial direction and in the increasing angle $\theta$, respectively. In order to approximate at each grid point the axial velocity and the streamfunction we follow a method proposed by Petrakis and Karahalios [12].

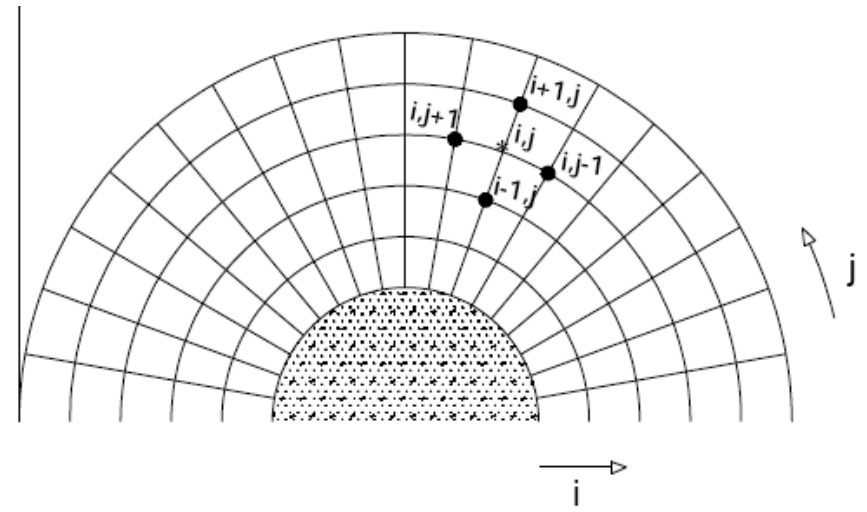

Fig. (2). Mesh points in $\mathrm{r}-\theta$ plane.

The final algebraic system was solved numerically using an iterative procedure, the successive over relaxation method. It is necessary to mention that the iterative scheme was repeated until the adopted criterion of accuracy for w, $\max \left|1-\frac{\mathrm{w}^{(\mathrm{s})}(\mathrm{r}, \theta)}{\mathrm{w}^{(\mathrm{s}+1)}(\mathrm{r}, \theta)}\right| \leq 5 \times 10^{-5}$ was satisfied. Then the values of $\mathrm{w}$ at all grid points were kept fixed and the iterative procedure was repeated only for the steamfunction $f$ until the predetermined limits to a corresponding degree of accuracy for the streamfunction was achieved. Once all quantities had converged to limits, the iterative sequence was terminated. For radius ratio $\mathrm{k}=2$ and $\mathrm{k}=5$, solutions were carried out for $\mathrm{D}=96,500, \ldots, 8000$, each one obtained using five different pairs of grid sizes. For $\mathrm{k}=10$ we obtained solutions for $\mathrm{D}$ up to 7000 , again with the same pairs of grid sizes ( (a) $h=\Delta r / 8$, $\mathrm{g}=\pi / 8$, (b) $\mathrm{h}=\Delta \mathrm{r} / 16, \mathrm{~g}=\pi / 16$, (c) $\mathrm{h}=\Delta \mathrm{r} / 32, \mathrm{~g}=\pi / 32$, (d) $\mathrm{h}=\Delta \mathrm{r} / 64, \mathrm{~g}=\pi / 64$ and (e) $\mathrm{h}=\Delta \mathrm{r} / 128, \mathrm{~g}=\pi / 128)$. Finally, in the case $\mathrm{k}=1000$ we employed only the first four pairs and we obtained solutions with D varying between 96 and 5000. It was realized that increasing the value of $\mathrm{k}$, resulted in the tendency of the whole procedure to be slower and to converge after a bigger number of iterations.

\section{RESULTS AND DISCUSSION}

In Fig. (3) we show the variation of the profiles of the non-dimensional axial velocity $w$ along the line of symmetry $\theta=0, \pi$ for various values of the Dean number $D$, in two cases for $\mathrm{k}$. In the case of a large core $(\mathrm{k}=2)$ (Fig. 3a) we see that the curves are nearly parabolic, the value of the axial (a)

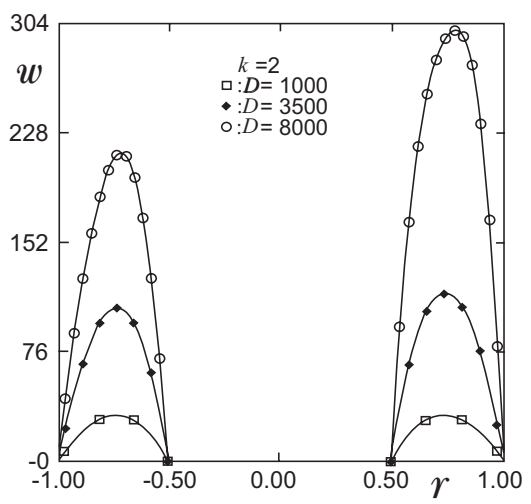

(b)

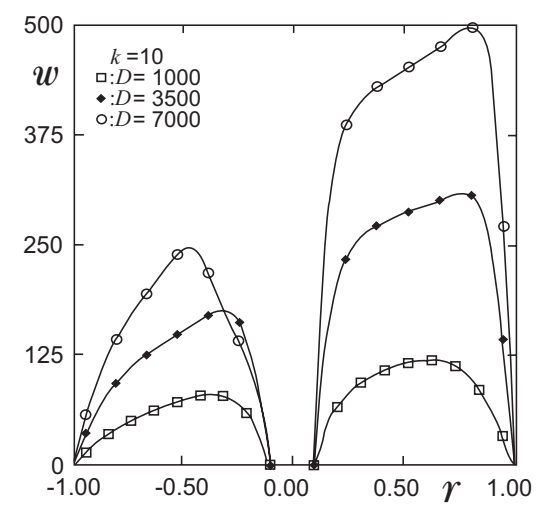

(c)

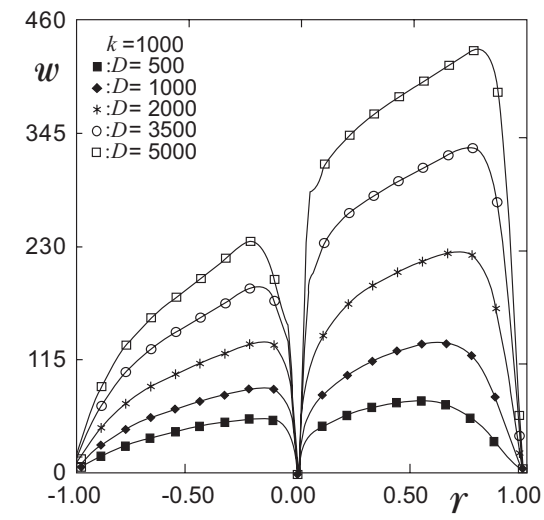

(d)

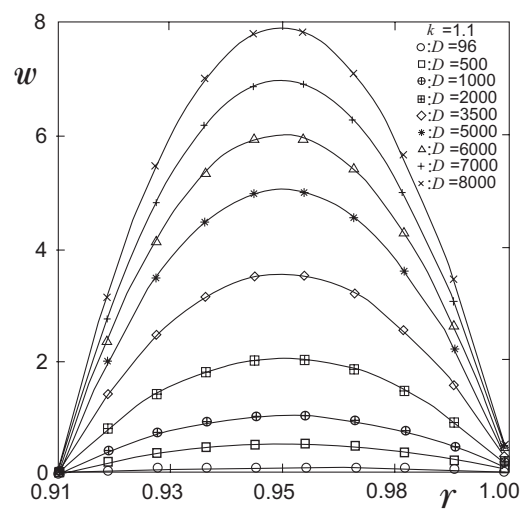

Fig. (3). Variation of the axial velocity profiles with $\mathrm{r}$. 
velocity being reduced compared with its corresponding value for the same value of $\mathrm{D}$ and a smaller core radius. The regions of the flow are not distinct and this is due to the small width of the annular gap. In the limit $\mathrm{k} \rightarrow 1$ (Fig. 3d), it is evidence that the flow is similar to the Couette-type flow.

When the core is smaller $(\mathrm{k}=10)$ (Fig. 3b), we see that the flow consists of a central inviscid region that the value of the axial velocity is invariable, while the maximum of the value of the axial velocity becomes larger as D increases. In Fig. (3c) we show the case for an even smaller core radius $(\mathrm{k}=1000)$.

Curves of constant axial velocity are plotted in Fig. (4) for $\mathrm{k}=2$ and for various values of the Dean number. The velocity profiles indicate that the isovelocity curves are circles concentric to the boundaries. As D increases the isovelocity curves form a separate loop in the outer part of the bend due to the centrifugal forces.

In Fig. (5) we have plotted the isovelocity curves for a small core radii $(k=10)$. The form of these curves indicates the development of a central inviscid region as D increases. The axial isovelocity lines become parallel over a significant part of the fluid in which part the effects of viscosity may be neglected.

The secondary flow pattern for $\mathrm{k}=2$ is shown in Fig. (6). The flow pattern indicates the effect of the Dean number and of the size of the core on the secondary flow itself. The formation of the system of four vortices is the result of the viscous character of the Stokes boundary layers that are formed along the two boundaries.

When $\mathrm{k}=10$ (Fig. 7) and for small values of Dean number two large vortices are formed, extending to the whole range of the fluid, and two smaller vortices close to the outer side of the inner boundary.

The maximum axial velocity occurs on the line of symmetry $\theta=0, \pi$. In Fig. (8) the variation of the position of $\mathrm{w}$ with $\mathrm{D}$ is shown for various values of the radius ratio $\mathrm{k}$. In the same figure we have added experimental results concerning the flow in a curved pipe, where $d$ denotes the non-dimensional distance of the position of $\mathrm{w}_{\max }$ from the centre of the cross-section of the tube. It is obvious that the agreement between experimental and numerical results is very good. In Fig. (9) we show the variation of $\mathrm{w}_{\max }$ with $\mathrm{D}$. It can be seen that as $\mathrm{k}$ increases our numerical results tent to coincide with experimental ones.

\section{CONCLUSIONS}

In the present work we approximate the Navier-Stokes equations of motion by means of a relaxation method. For a large core radii $\mathrm{k}=2$, our method is valid for values of $\mathrm{D}$ up to 8000 , while for smaller radius ratios the value of $\mathrm{D}$ for which convergence is possible was less than 7000 for $\mathrm{k}=10$ and 5000 for $\mathrm{k}=1000$.

When the radius of the core is small $(k=2)$ the flow pattern resembles to the Couette-type flow, while the (a)

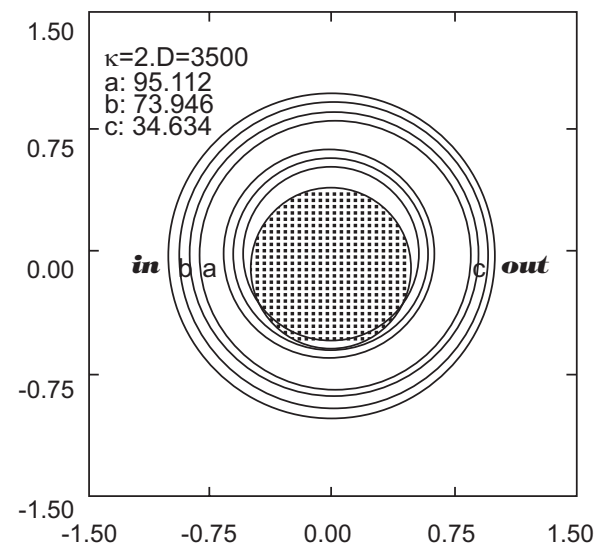

(b)

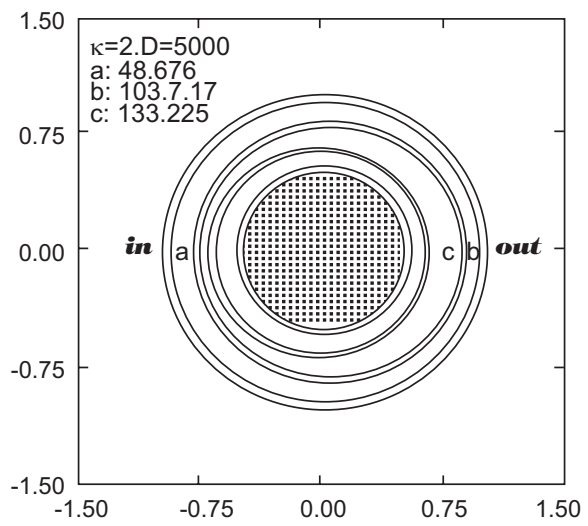

(c)

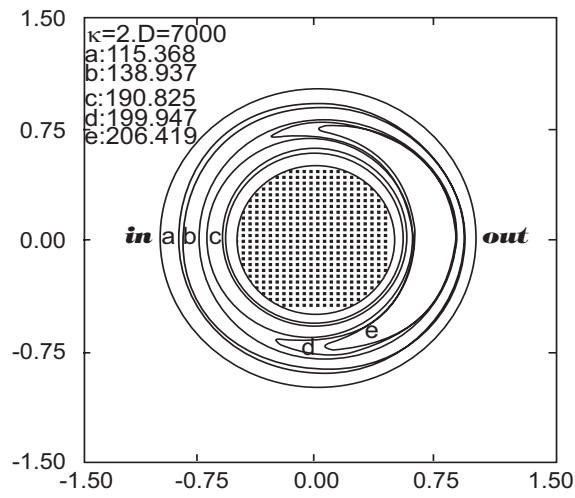

(d)

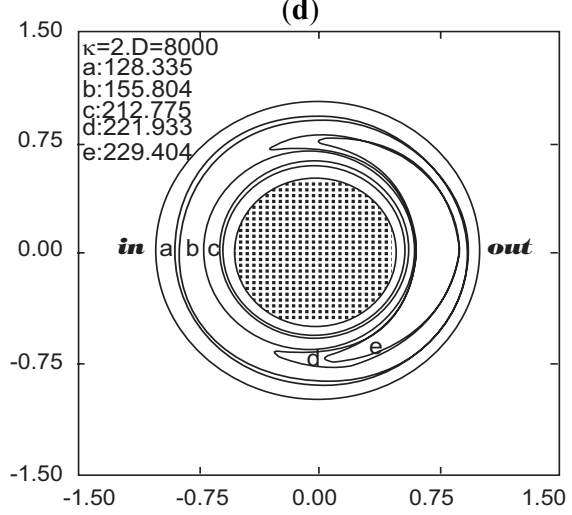

Fig. (4). Isovelocity curves for $\mathrm{k}=2$. 
(a)

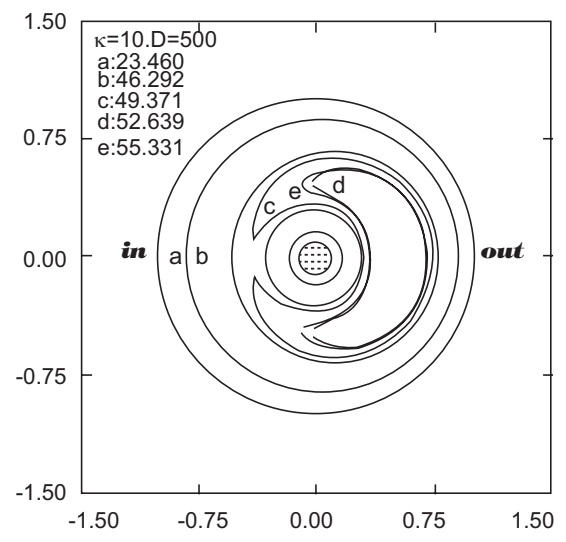

(b)

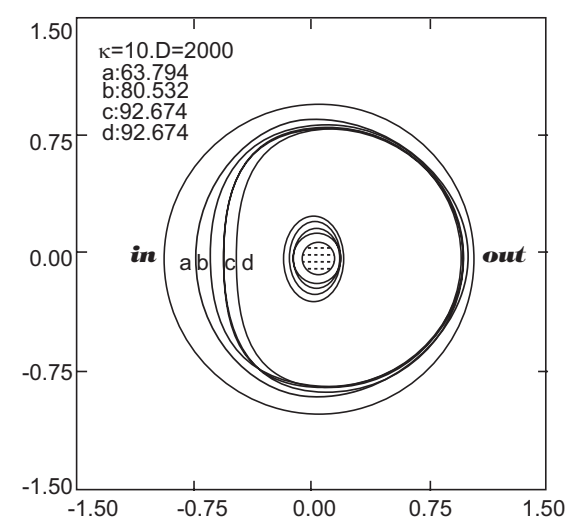

(c)

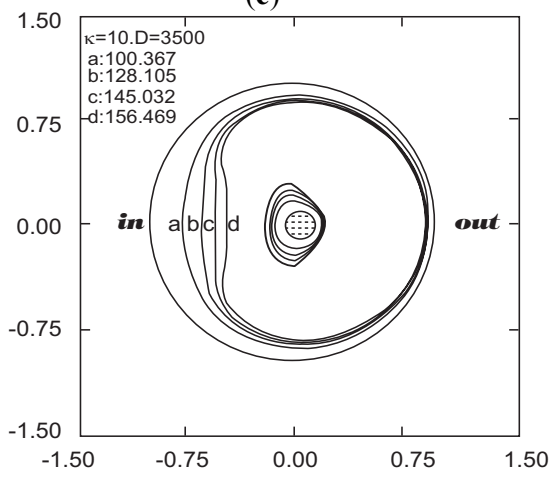

(d)

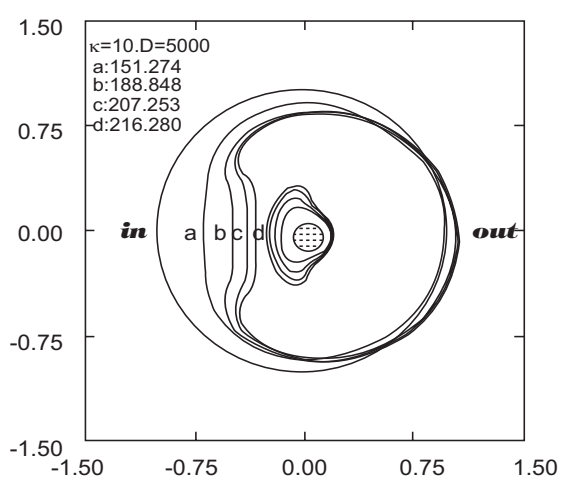

Fig. (5). Isovelocity curves for $\mathrm{k}=10$. (a)

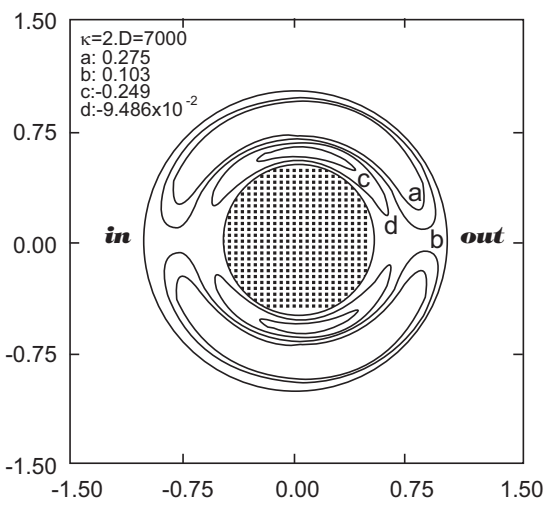

(b)

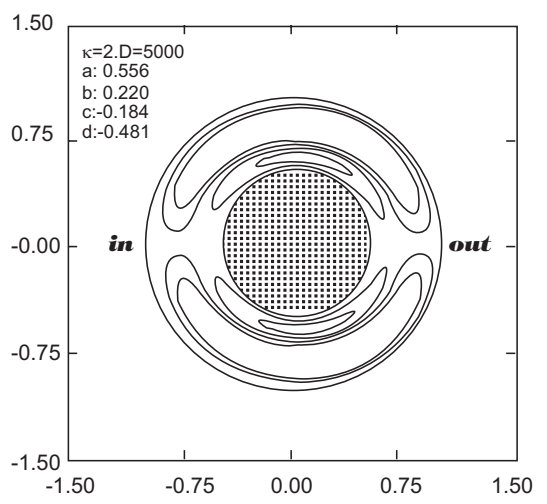

(c)

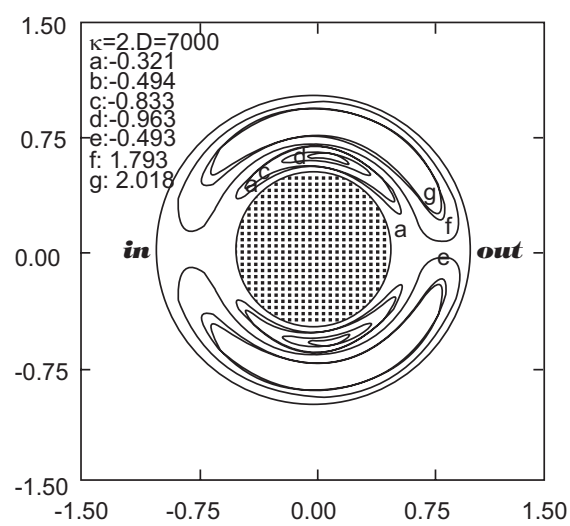

(d)

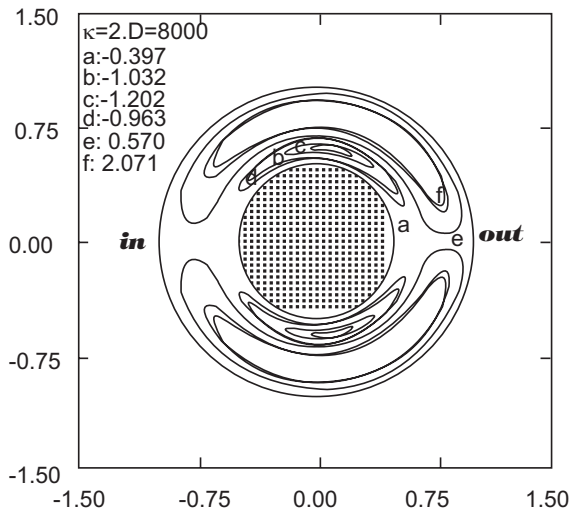

Fig. (6). Secondary flow pattern for $\mathrm{k}=2$. 
(a)

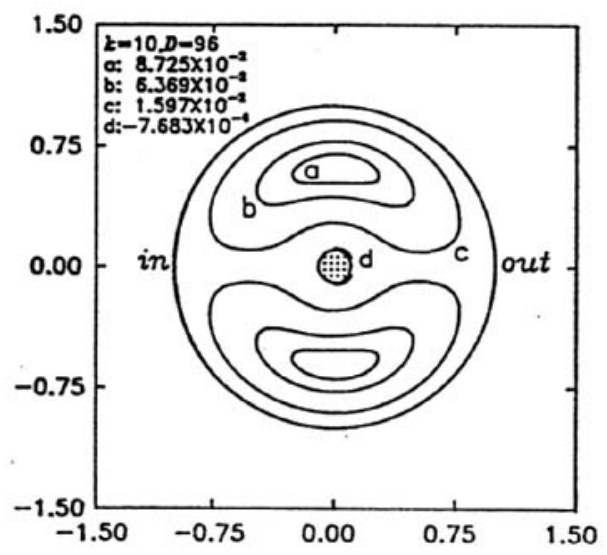

(b)

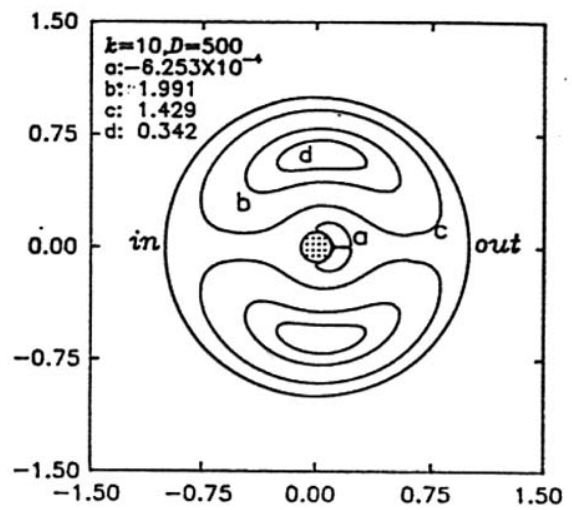

(c)

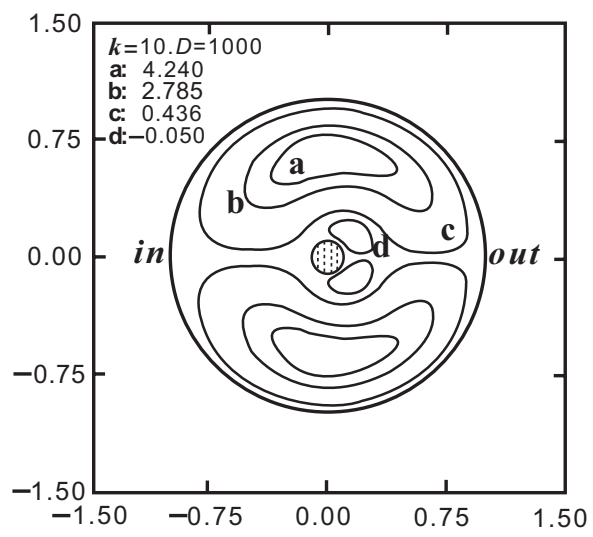

(d)

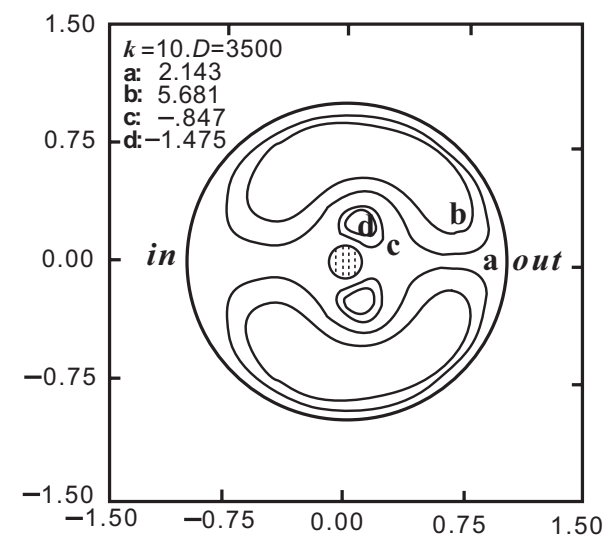

Fig. (7). Secondary flow pattern for $k=10$. variation of the Dean number does not affect seriously the form of the axial and secondary flow. As the radius of the core increases $(\mathrm{k}=10)$ the flow depends on the Dean number. When D increases the both the boundary layers on the pipe and on the core become thinner. There is an inviscid region of the flow due to the small radius of the core and the well known system of four vortices is appear. Finally, numerical and experimental results are in a very good agreement, in the case of $\mathrm{k} \rightarrow 1000$.

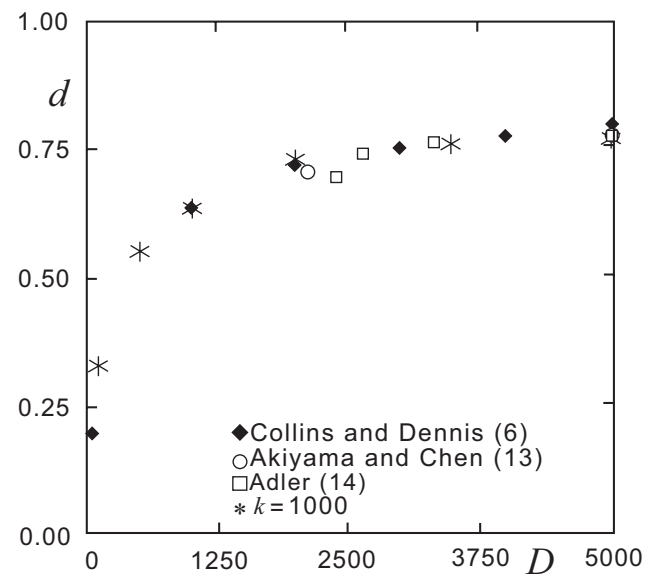

Fig. (8). Variation of the position $\mathrm{d}$ of $\mathrm{w}_{\max }$ with the Dean number.

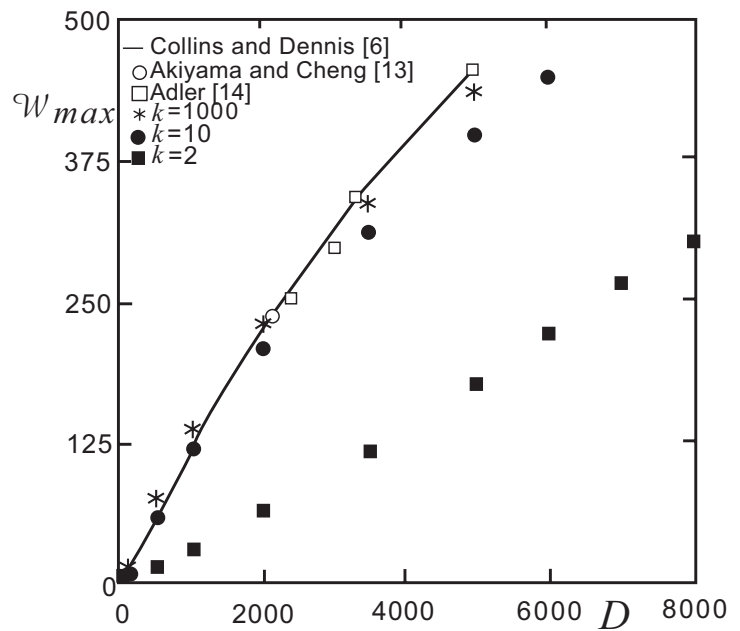

Fig. (9). Variation of $\mathrm{w}_{\max }$ with the Dean number.

\section{REFERENCES}

[1] Dean, W.R. Note on the motion of fluid in curved pipes. Philos. Mag., 1927, 20, 208-223.

[2] Dean, W.R. The streamline motion of fluid in a curved pipe Philos. Mag., 1928, 30, 673-693.

[3] McConalogue, D.J.; Srivastava. Motion of fluid in a curved tube. R.S. Proc. Royal Soc. London, Ser. A, 1968, 307, 37-53.

[4] Truesdell, L.C.; Adler, R.J. Numerical treatment of fully developed laminar flow in helically coiled tubes. A I Ch $E J, \mathbf{1 9 7 0}, 16,1010-$ 1015.

[5] Greenspan, A.D. Secondary flow in a curved tube. J. Fluid Mech., 1973, 57, 167-176.

[6] Collins, W.M.; Dennis, S.C.R. The steady motion of a viscous fluid in a curved tube. Quart. J. Mech. Appl. Math, 1975, 28, 133-156.

[7] Dennis, S.C.R. Calculation of the steady flow through a curved tube using a new finite-difference method. Quart. J. Fluid Mech., 1980, 99, 499-467. 
[8] Karahalios, G.T. Mixed convection flow in a heated curved pipe with core. Phys. Fluids, 1990, A 2, 2164-2175.

[9] Choi,H.K; Park, S.O. A numerical study of mixed convctive heat transfer in a curved annulus. Proc. $2^{\text {nd }}$ JSME-KSME, 1, 85-88, 1992.

[10] Karahalios, G.T.; Petrakis, M.A. Fully developed stedy flow in a slightly curved annular pipe. Acta Mechanica, 1991, 88, 1-10.

[11] Allen, D.N.; Southwell, R.V. Relaxation methods applied to determine the motion. Qtr. J. Mech. Appl. Math., 1955, 8, 129-145.
[12]

Petrakis, M.A.; Karahalios, G.T. Fluid flow behavior in a curved annular conduit. Int. J. Non Linear Mech., 1999, 34, 13-25.

[13] Akiyama, M; Cheng, K.C. Boundary vorticity method for laminar forced convection heat transfer in curved pipes. Int. J. Heat Mass Transfer, 1971, 14, 1659-1675.

[14] Adler, M. Stromung in gekrummten Rohren. Z. Angew. Math. Mech., 1934, 14, 257-275.

Received: December 15, 2008

Revised: February 6, 2009

Accepted: February 11, 2009

(C) Petrakis et al.; Licensee Bentham Open.

This is an open access article licensed under the terms of the Creative Commons Attribution Non-Commercial License (http://creativecommons.org/licenses/by$\mathrm{nc} / 3.0 /$ ) which permits unrestricted, non-commercial use, distribution and reproduction in any medium, provided the work is properly cited. 